(akademik, hakemli, indexli, uluslararası dergi)

\title{
ALTERNATİF BİR BÜTÇELEME MODELİ: SÜRÜCÜ TEMELLİ BÜTÇELEME
}

\author{
Dr. Öğr. Ü. İbrahim APAK*
}

\section{$\ddot{\mathbf{O z}}$}

$\mathrm{Bu}$ çalışmanın amacı bütçeleme yaklaşımlarına bir alternatif olarak geliştirilen sürücü temelli bütçeleme modelinin kavramsal olarak ele alınmasıdır. Çalışmada kapsamlı bir literatür taraması gerçekleştirilerek sürücü temelli bütçelemenin kapsamı, avantajları, dezavantajları ve modelleri üzerinde durulmaktadır. Sürücü temelli bütçeleme modelinin öne çıkan en belirgin özelliklerinin esneklik, hız ve maliyet avantajı olduğunu söylemek mümkündür. Uygulayıcılar açısından en dezavantajlı yönü ise sürücü temelli bütçeleme modelinin henüz bilinmemesi ve değişime olası direnç olarak ifade edilebilir. Sürücü temelli bütçeleme modelinin bütün işletme birimlerince benimsenmesi ve uygulama adımlarının gerçekleştirilmesi işletmeler için oldukça yararlı olacaktır.

Anahtar Kelimeler: Bütçe, Planlama, Sürücü temelli bütçeleme.

\section{AN ALTERNATIVE BUDGETING MODEL: THE DRIVER-BASED BUDGETING}

\section{Abstract}

This study aims to conceptually examine the driver-based budgeting model, which is developed as an alternative to budgeting approaches. In the study, a comprehensive literature review is carried out and the scope, advantages, disadvantages, and models of driver-based budgeting are emphasized. It is possible to say that the most prominent features of the driver-based budgeting model are flexibility, speed, and cost advantage. The most disadvantageous aspect for practitioners is that the driver-based model is not well known yet and it can be expressed as possible resistance to change. If the driverbased budgeting model is adopted by all business units and implementation steps are carried out, it will be very useful for businesses.

Keywords: Budget, Planning, Driver-based budgeting.

\footnotetext{
* Aksaray Üniversitesi, Sosyal Bilimler Meslek Yüksekokulu, Muhasebe ve Vergi Uygulamaları Bölümü, Orcid: 00000002-5404-0361 apakibrahim@gmail.com 


\section{GIRIŞ̧}

Geleneksel bütçeleme, esnek olmaması ve statik yapıda olması nedeniyle kendisinden beklenen faydaları sağlama konusunda yetersiz kalmaktadır. Dolayısıyla değişen işletme koşullarına uygun, etkin ve dinamik bir araç olarak katkı sağlayamamaktadır (Leon, Rafferty, \& Herschel, 2012). İşletme çevresinde meydana gelen değişimler bütçeleme araçlarının kullanımında çok sayıda sorunlara yol açmaktadır. Söz konusu sorunların çözülebilmesi, piyasa koşullarına daha kolay ve hızlı yanıt vererek işletme faaliyetlerinin daha etkin bir şekilde yerine getirilebilmesine imkân sağlayabilecek bütçeleme araçlarının geliştirilmesini gerektirmektedir (Nikodijević, 2021).

Geleneksel bütçeleme araçlarına getirilen eleştirilerin başında esneklik konusunun olduğunu söylemek mümkündür. Geleneksel bütçeleme uygulayıcısı bir işletmede, bütçelerin hazırlandığı tarih ile uygulandığı tarih arasında büyük bir zaman farkı bulunmaktadır. Günümüz şartları değerlendirildiğinde -çoğunlukla- yıllık olarak hazırlanan bir bütçenin beklentileri karşılamasının güç olacağı aşikârdır. Bu nedenle değişken işletme çevresine hızlı bir biçimde uyum sağlayabilen bütçeleme araçlarına ihtiyaç duyulmaktadır (Coombs, Hobbs, \& Jenkins, 2005, s. 137-138).

Geleneksel bütçeleme araçlarının eleştirilen (veya yetersiz) yönlerini gidermek amacıyla çeşitli araçlar, teknikler veya yaklaşımlar geliştirilmiştir (Becker, Messner, \& Schäffer, 2009). Geleneksel bütçelemeye alternatif olarak sürekli bütçeleme (Eaton, 2005, s. 6), faaliyet tabanlı bütçeleme, sıfır tabanlı bütçeleme (Rickards, 2006), bütçe ötesi yönetim (Bogsnes, 2016, s. 3-4) gibi çeşitli bütçeleme araçları geliştirilmiştir. Geleneksel bütçeleme araçlarının günümüz değişen ve gelişen iş dünyasında eleştirilen (veya yetersiz) yönlerini gidermek amacıyla geliştirilen bütçeleme yaklaşımlarından birisi de sürücü temelli bütçeleme modelidir."

\section{SÜRÜCÜ TEMELLİ BÜTÇELEME - KAVRAM}

Sürücü temelli bütçeleme, yönetsel karar verme süreçleriyle doğrudan ilişkili bir bütçeleme modelidir. Bu bütçeleme modelinin temelinde işletme performansı ile ilişkili faaliyetler ve kontrol edilebilir değişkenler üzerine odaklanılarak planlama sürecinin yürütülmesi yer almaktadır (Leon, Rafferty, \& Herschel, 2012). Bu sayede işletme yöneticileri işletme performansının geleceği noktasında daha kesin bir görünüm elde edebilmektedir.

Deloitte (2021) sürücü temelli bütçelemeyi, "finansal tahminleri operasyonel sürücülere (faaliyet etkenlerine) dayandıran bir yaklaşım” olarak tanımlamaktadır. Sürücü temelli bütçeleme, yüksek

\footnotetext{
"Yaklaşımın İngilizce karşılığı "driver-based budgeting” olarak kaynaklarda yer almaktadır. Ayrıca "driver-based planning", "driver-based forecasting" ve "driver-based modelling" olarak kullanımları da mevcuttur. Bütçeleme kavramı içerisinde planlama ve tahmin etme eylemlerini de içerdiği için (ayrıca kavram karmaşasının önüne geçilmesi amacıyla) bu çalışmada "sürücü temelli bütçeleme" olarak ele alınmaktadır.
} 
$\ldots$ (akademik, hakemli, indexli, uluslararası dergi)

düzeyde güvenilirlik, verimlilik, esneklik, değişikliklere yanıt verebilme ve stratejik uyum özelliklerine sahiptir (Nikodijević, 2021). Ayrıca, sürücü temelli bütçeleme, sürekli güncellenen tahminler (rolling forecast) ve finansal öngörüler gerçekleştirmek için kullanılabilmektedir. Bu bütçeleme yaklaşımında yöneticilerin tahmin ve öngörülerinden ziyade, nihai sonuçlar üzerinde etkili sürücüler (faktörler) hesaplamalara katılarak bütçeler oluşturulmaktadır (Menon \& Thomas, 2021).

Sürücü temelli bütçeleme, bağımlı ve bağımsız değişkenlerden oluşan modellerin çıktıları üzerinden söz konusu değişkenler arasındaki neden sonuç ilişkisinin anlaşılması ile doğrudan ilgilidir. $\mathrm{Bu}$ konuda getirilebilecek en basit örnek, oranlar ve birimlerle satışların tahmin edilmesidir. Sürücü temelli bütçeleme modellerinin öne çıkan özelliği kolay ve hızlı bir şekilde durum analizine izin vermesidir. Örneğin, 12 aylık satışlarının bütçelemesini (planlamasını) yapmış olan bir işletme varsayalım. Şubat ayından itibaren satışlarda \%10'luk düşüş olması durumunda işletmede yol açacağı ek maliyet (veya bütçe sapmaları) sonucunda planlanan çıktılara ulaşılabilmesi için alınması gereken aksiyonlar önceden planlanabilir ve uygulamaya konulabilir. Benzer şekilde işletmede önemli bir maliyet olduğunu varsaydığımız petrol fiyatlarındaki \%10 artışın işletmede yol açacağı ek maliyetin (veya bütçe sapmalarının) yönetilebilmesi için farklı birimlere düşen hedefler planlanabilir. Dolayısıyla sürücü temelli bütçeleme modelleri önemli ölçüde esneklik sağlayabilmektedir (Sanchez, 2020).

İşlemelerde kullanılan bütçeleme teknikleri zaman içerisinde çeşitli eleştirilere maruz kalmaktadır. $\mathrm{Bu}$ süreç içerisinde eleştirilen bütçeleme tekniklerinin yerlerini yeni geliştirilen bütçeleme teknikleri almaktadır (Becker, Messner, \& Schäffer, 2009). Geleneksel bütçeleme yöntemleri ile sürücü temelli bütçelemenin karşılaştırılması modelin daha iyi anlaşılması için önem arz etmektedir. Tablo 1'de geleneksel bütçeleme yöntemleri ile sürücü temelli bütçeleme kıyaslamasına yer verilmektedir.

Tablo 1. Geleneksel Bütçeleme - Sürücü Temelli Bütçeleme

\begin{tabular}{|l|l|}
\hline Geleneksel Bütçeleme & Sürücü Temelli Bütçeleme \\
\hline Uygulaması zaman alıcı ve maliyetlidir. & Bütçeleme döngülerini azaltır. \\
\hline $\begin{array}{l}\text { Bütçelerdeki duyarlılığı ve esnekliği kısıtladığından } \\
\text { genellikle değişimin önünde bir engel haline gelir. }\end{array}$ & Departmanlar arası koordinasyonu sağlar. \\
\hline $\begin{array}{l}\text { Nadiren stratejik olarak odaklanmış ve çoğu zaman } \\
\text { strateji ile uyumsuzdur. }\end{array}$ & $\begin{array}{l}\text { Tahmine dayalı planlama kurallarında stratejik } \\
\text { varsayımlar yapılabildiği için stratejiyle uyumlu hale } \\
\text { getirilebilir. }\end{array}$ \\
\hline $\begin{array}{l}\text { Hazırlama süreleri ile kıyaslandığında işletmelere çok } \\
\text { az katkı sağlamaktadır. }\end{array}$ & $\begin{array}{l}\text { Planlama ve bütçeleme sürecine ilişkin yönetim } \\
\text { anlayışını artırır. Yöneticilerin ihtiyaç duyulan } \\
\text { hizmeti sunmak için gereken kaynakları planlamasına } \\
\text { yardımcı olur. }\end{array}$ \\
\hline $\begin{array}{l}\text { Değer meydana getirmek yerine maliyet kontrolüne } \\
\text { odaklanmaktadır. }\end{array}$ & $\begin{array}{l}\text { Maliyet kontrolüne odaklanır, ancak maliyeti hizmet } \\
\text { sunumuyla dengeler. }\end{array}$ \\
\hline
\end{tabular}


... (akademik, hakemli, indexli, uluslararası dergi)

\begin{tabular}{|c|c|}
\hline $\begin{array}{l}\text { Komuta ve kontrol ile ilişkili dikey hiyerarşiyi } \\
\text { güçlendirir. }\end{array}$ & $\begin{array}{l}\text { Yönetimle bağlıdır, ancak müşteri gereksinimlerini } \\
\text { karşılamak için faaliyetlerin çapraz fonksiyonel } \\
\text { koordinasyonuna izin verir. }\end{array}$ \\
\hline $\begin{array}{l}\text { İşletmelerin günümüzde benimsediği ağ yapılarını } \\
\text { yansıtmamaktadır. }\end{array}$ & $\begin{array}{l}\text { Bir ağ yapısındaki yöneticilerin tek bir planla } \\
\text { etkileşim kurmasını sağlayan merkezi bir açık bütçe } \\
\text { ortamı oluşturur. }\end{array}$ \\
\hline $\begin{array}{l}\text { Hedef belirlemede "kumar" davranışını teşvik } \\
\text { ederek, işletme ihtiyacına göre belirlenmeyen; } \\
\text { üzerinde anlaşmaya varılan hedefler ortaya çıkarır. }\end{array}$ & $\begin{array}{l}\text { Planlar ve bütçeler gerçek faaliyetlerle bağlantılı } \\
\text { olduğundan "kumar" oynamayı çok daha zor hale } \\
\text { getirir. }\end{array}$ \\
\hline $\begin{array}{l}\text { İşletme faaliyetleri için çok seyrek olarak } \\
\text { geliştiriliyor, gözden geçiriliyor ve güncelleniyor. }\end{array}$ & $\begin{array}{l}\text { Hızla gözden geçirilebilir ve güncellenebilir, birim } \\
\text { bütçelerinde beklenmedik değişiklikler meydana } \\
\text { geldiğinde işletme genel bütçe revizyonlarını hızla } \\
\text { yönetmesine ve iletmesine olanak tanır. }\end{array}$ \\
\hline $\begin{array}{l}\text { Gerçek performans verileri üzerine inşa edilmek } \\
\text { yerine test edilmemiş varsayımlara ve tahminlere } \\
\text { dayalıdır. }\end{array}$ & Gerçek performans verileri üzerine inşa edilmiştir. \\
\hline $\begin{array}{l}\text { Departmanlar arası işbirliğini ve bilgi paylaşımını } \\
\text { teşvik etmek yerine departmanlar arasındaki engelleri } \\
\text { güçlendirmektedir. }\end{array}$ & $\begin{array}{l}\text { Farklı departmanlar ve birimler arasındaki faaliyetleri } \\
\text { koordine ederek engelleri ortadan kaldırır. }\end{array}$ \\
\hline $\begin{array}{l}\text { Çalışanları varlık yerine maliyet olarak } \\
\text { değerlendirdiği için çalışanlara kendilerini değersiz } \\
\text { hissettirmektedir. }\end{array}$ & $\begin{array}{l}\text { İnsanları faaliyetler gerçekleştiren, ürün ve hizmetler } \\
\text { yaratan, ancak maliyeti olan bir kaynağa dönüştürür. }\end{array}$ \\
\hline
\end{tabular}

Kaynak: (https://www.icaew.com/, 2021)

Tablo 1'de yer alan kıyaslama ele alındığında sürücü temelli bütçelemenin esneklik, geleceğe ilişkin daha kesin tahminler ve işletme birimlerinin koordinasyonunun sağlanması konusunda yararlarının öne çıktığını söylemek mümkündür. Ayrıca maliyet avantajı konusunda da işletmeye yarar sağlamaktadır (Hariharan, 2017). Sürücü temelli bütçelemenin avantajlarını daha spesifik biçimde ele alacak olursak (Barrett, 2007, s. 87-95):

- Bütçeleme ve bütçe güncelleme sürelerini kısaltır,

- Daha az tekrar eden işlemler içerir,

- Maliyet avantajı sağlar,

- Yöneticilerin hesap verebilirliğini artırır,

- Takvim yılına mecbur kalınmasının önüne geçer,

- İşletme için içgörü ve çeviklik sağlar,

- Riski azaltır,

- Geçmiş verilere dayanılarak geleceği tahmin etme eylemini (ekstrapolasyon) minimize eder,

- Daha doğru, kesin bilgi verir,

- Atıl kapasiteyi azaltmaya yardımcı olur,

- İşletmelerin daha sık tahminlerde bulunmasına imkân sağlar, 
- Bütçelemeyi "kumar” davranışı olarak görmeyi azaltır.

Wolf (2015) sürücü temelli bütçelemenin temel faydalarını şu şekilde sıralamaktadır. İşletmelere önde gelen ve gecikmeli göstergelere odaklanan model dizayn etme imkânı sağlar, işletmede gerçekleşen eylemlerle ilgili daha geniş öngörü sağlar, planlayıcılara sürücüler yardımıyla alternatif senaryoları değerlendirme imkânı sağlar ve geleceğe ilişkin tahminlerin keskinliğini artırır. Sürücü temelli bütçelemenin yukarıda sıralanan faydalarının yanı sıra bir takım dezavantajlarıda bulunmaktadır. Bunlar (Barrett, 2007, s. 95-102):

- Uygulaması zor olarak algılanmaktadır,

- Geleneksel bütçelemelere odaklanmış uygulayıcılar yaklaşımın kurallarını bilmemektedir,

- Kullanımını sürdürmek nispeten zordur,

- Yönetimi bir süreç olarak görmeyi gerektirir,

- Değişmez olarak algılanmaktadır,

- Bazı işletme birimleri veya işletmeler kendilerini yatkın görmemektedir,

- Bazı insanlar yaklaşımın kullanımı ile birlikte gelecek şeffaflıktan dolayı kendilerini rahat hissetmeyebilmektedir.

Sürücü temelli bütçelemenin işletmelerce kullanımında karşılaşılabilecek güçlüklerden birisi de bütçeleme sisteminin değişimi aşamasında bütün organizasyonel yapının yeniden şekillendirilmesidir. $\mathrm{Bu}$ süreçte hem işletme yönetimi hem de birimler sürücü temelli bütçeleme uygulamasında kendilerine düşen rolü anlamak durumundadır. Özellikle sürücülerin belirlenmesinde bütün işletme birimleri sürece dâhil olarak katkı sunmalıdır. Aksi durumda yaklaşımdan beklenen faydaları sağlamak güç olacaktır (Deloitte, 2021).

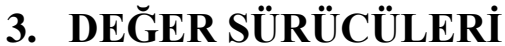

Sürücü temelli bütçeleme modelinde üzerinde durulması gereken önemli bir unsur "sürücü" konusudur. Barrett (2007, s. 62) sürücü temelli bütçelemede "sürücü”yü, “değişstirildiğinde doğrudan ya gelirler ya da giderleri etkileyen; bunun sonucunda da bütçelenen kâr ve zarar tablosunu, nakit akışını ve bilançoyu değiştiren finansal veya finansal olmayan veri parçasıdır" olarak tanımlamaktadır. Faaliyet tabanlı maliyetleme yaklaşımında kullanılan sürücüler bir yönüyle sürücü temelli bütçelemede kullanılan sürücülerle aynıdır. Sürücü temelli bütçelemede kullanılan sürücüleri faaliyet tabanlı maliyetlemede kullanılan sürücülerden ayıran temel fark sürücülerin doğrudan gelirler ya da giderleri etkilemesidir (Barrett, 2007, s. 63). 


\section{... (akademik, hakemli, indexli, uluslararası dergi)}

Sürücü temelli bütçelemenin bir işletmede kullanılabilmesi için faaliyet tabanlı maliyetleme

kullanılması bir gereklilik değildir. Halihazırda işletmede faaliyet tabanlı maliyetleme'nin kullanılıyor olması, sürücü temelli bütçelemeye adapte olunmasını kolaylaştıracak ve hızlandıracaktır. Hem sürücü temelli bütçeleme hem de faaliyet tabanlı maliyetleme kullanılan bir işletmede bu iki araç arasında sürekli senkronizasyonun sağlanması gerekmektedir (Deloitte, 2021). Tablo 2'de bir işletmede sürücü temelli bütçeleme uygulamasında kullanılabilecek sürücü çeşitlerine ve örneklerine yer verilmektedir.

\section{Tablo 2. Sürücü Çeşitleri ve Örnekler}

\begin{tabular}{|c|c|c|}
\hline Sürücü Çeşitleri & Kapsamı & Örnekler \\
\hline Kantitatif talep ölçüleri & $\begin{array}{l}\text { Satılan ürünler/hizmetler için } \\
\text { tahmin edilen talep seviyesini } \\
\text { ve işletme departmanların ayrı } \\
\text { ayrı karşılaştığı talep } \\
\text { seviyesini içermektedir. }\end{array}$ & $\begin{array}{l}\text { Pazar büyüklüğü ve pazar payı, } \\
\text { Ürün satış miktarı, } \\
\text { Gelen telefon görüşmesi sayısı, } \\
\text { Takip edilecek gecikmiş ödeme sayısı, } \\
\text { Aktif müşteri sayısı, } \\
\text { Sipariş başına (satı̧̧) ürün sayısı, } \\
\text { Potansiyel müşterilere gönderilen doğrudan posta } \\
\text { sayısı. }\end{array}$ \\
\hline $\begin{array}{l}\text { Tüketim oranları, üretkenlik } \\
\text { oranları veya çevrim süreleri }\end{array}$ & $\begin{array}{l}\text { Talebi karşılamak veya bir } \\
\text { birim çıktı üretmek için } \\
\text { gereken kaynak miktarını } \\
\text { ölçmektedir. }\end{array}$ & $\begin{array}{l}\text { Günlük temsilci başına çağrı sayısı gibi basit } \\
\text { üretkenlik oranları, } \\
\text { Bir görüşmenin ortalama süresi gibi döngü } \\
\text { süreleri, } \\
\text { Yönetici çalışan oranı. }\end{array}$ \\
\hline Birim kaynak maliyetleri & $\begin{array}{l}\text { Bir dönem boyunca bir kaynak } \\
\text { biriminin ortalama maliyeti. }\end{array}$ & $\begin{array}{l}\text { Birim yakıt maliyeti, } \\
\text { Belirli bir personel grubunun ortalama maaş } \\
\text { maliyeti, } \\
\text { Bir bilgisayarın öngörülen değiştirme maliyeti. }\end{array}$ \\
\hline Birim satış fiyatları & $\begin{array}{l}\text { Bir ürün veya hizmetin } \\
\text { ortalama satış fiyatı. }\end{array}$ & $\begin{array}{l}\text { Belirli bir sigorta poliçesinin ortalama primi, } \\
\text { Her bir danışmanlık sözleşmesi için öngörülen } \\
\text { ücret, } \\
\text { Belirli bir ürün için beklenen satış fiyatı. }\end{array}$ \\
\hline $\begin{array}{l}\text { Modellemede kullanılan diğer } \\
\text { sürücüler }\end{array}$ & Olasılıklar ve yüzdeler & $\begin{array}{l}\text { Satışla sonuçlanan gelen telefon çağrılarının } \\
\text { oranı. } \\
\text { Aktif müşteri sayısını modellemek ve ardından } \\
\text { beklenen geliri tahmin etmek için } \\
\text { kullanılabilecek, öngörülen müşteri yıpranma } \\
\text { oranı. } \\
\text { Poliçe sahiplerinin sigorta poliçeleri üzerinde bir } \\
\text { talepte bulunma olasılığı. } \\
\text { İlgili ay boyunca faturalanan yeni satışların oranı. }\end{array}$ \\
\hline
\end{tabular}

Kaynak: (Barrett, 2007, s. 63-64)'den yararlanılarak oluşturulmuştur.

Her işletme için belirli çeşit ve sayıda sürücü bulunmamaktadır. Başka bir ifadeyle, sürücü temelli bütçeleme uygulamasında her işletme kendi işletme yapısına ve süreçlerine uygun olan sürücüleri ve sayısını kendisi belirlemelidir. Örneğin hizmet üretimi yapan bir teknoloji işletmesi için ihtiyaç duyulan sürücü türleri ve sayısı tüketim malları üreten gıda işletmesi için uygun olmayabilir (Deloitte, 2021). 
The Hackett Group tarafından 2015 yılında yapılan araştırmaya göre işletmelerin \%78'i sürücü temelli bütçelemeyi kullanmaktadır. Bu işletmelerde en çok kullanılan sürücüler sırasıyla: gelir, nakit akış, satış hacmi, satışların maliyeti, kazanç, çalışa sermayesi, brüt kâr, sermaye harcamaları, amortisman, kullanılan sermayenin getirisi, genel yönetim giderleri, satış ve pazarlama giderleri, araştırma ve geliştirme giderleri, olarak tespit edilmiştir (Essaides, 2016).

Sürücü temelli bütçeleme uygulamasında işletmeler çeşitli sürücüler arasından kendileri için uygun olanları seçmek durumundadır. Finansal ve operasyonel sürücü örnekleri şu şekilde sıralanabilir: finansal sürücüler: fiyat, miktar, kâr, satışların maliyeti. Operasyonel sürücüler: talep hacmi, personel devir hızı, hizmet düzeyi, tamamlanan satış yüzdesi (Sanchez, 2020). Bunların yanı sıra işletme içi ve dışı ile ilgili sürücüler şeklinde bir ayrım yapılarak işletme sürücülerinden bahsetmek mümkündür. Örneğin, işletme içi ile ilgili sürücüler: ortalama müşteri sayısı, çalışan sayısı, gezi, etkinlik sayıları. İşletme dışı ile ilgili sürücüler: petrol fiyatları, döviz kurları, iklim şartları (Melnychuk, 2017).

\subsection{Değer Sürücü Ağacı (Ăğı)}

İşletme üst yönetimi finansal planlama hedefleri ile örgüt stratejisi ve değer sürücülerini eşgüdümlemelidir. Başka bir ifadeyle bu üç unsur planlanırken ve uygulamaya konulurken birlikte hareket edebilecek şekilde tasarlanmalıdır. Bu uyumun olmaması durumunda bütçeleme yönetime yol gösteren ve yardımcı olan bir araçtan çok finansal bir aktiviteye (etkinliğe) dönecektir (Miller \& Galeaz, 2007). Bu nedenle öncellikle işletmede sürücüler belirlenmelidir. Bu noktada işletmenin değer sürücü ağacının (ağı) oluşturulması ve bununla birlikte sürücülerin belirlenmesi gerekmektedir.

Değer sürücü ağacı (ağı) en yalın haliyle "neden-sonuç ilişkileri zinciri" olarak ifade edilebilir. Örneğin A öğesi B öğesini etkiler, bunun sonucunda işletme performansı ve değeri artar (veya azalır) şeklindeki formülasyonlar (senaryolar) değer sürücü ağacı olarak adlandırılır. Bu ağ içerisinde her bir adım bir değer sürücüsüdür. Çünkü bu zincir halkalarının sonunda işletme değerinde artış (veya azalış) yer almaktadır (Burrows, 2021). Şekil 1'de net kâr için bir değer sürücü ağacı örneği yer almaktadır. 
Şekil 1. Değer Sürücü Ağacı (Ağı) Örneği

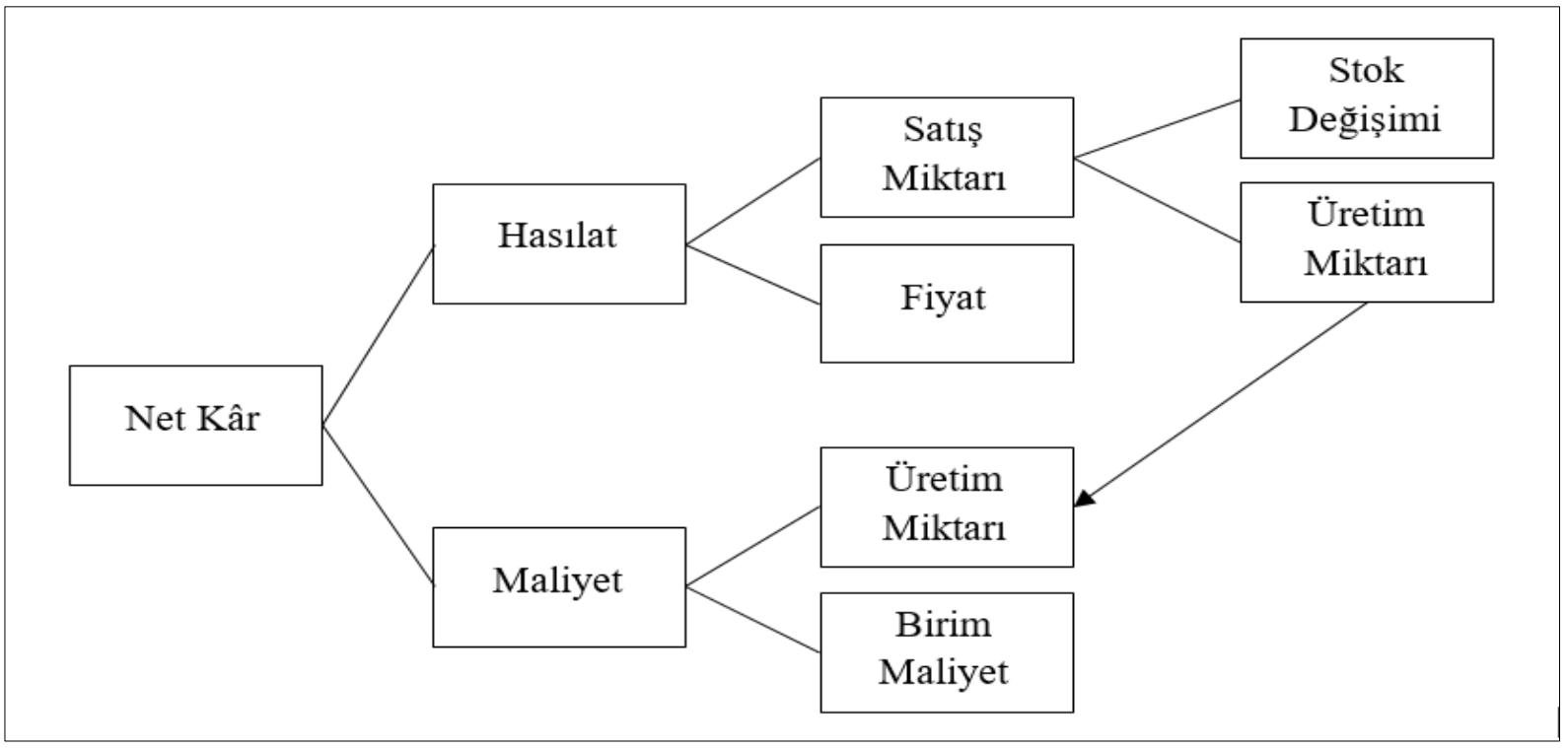

Kaynak: (https://valq.com/, 2021)

İşletmeler sürücü temelli bütçeleme ve tahmin etme modellerine geçiş yaparken değer sürücülerinin ölçüm süreçlerine odaklanmakta ve bu sürücülerin iyi anlaşılması için çaba harcamaktadır. Çünkü bu noktada işletme performansı için kritik öneme sahip sürücülerin tespit edilmesi oldukça önemlidir (Miller \& Galeaz, 2007). Şekil 1'de yer alan değer sürücü ağını nedensonuç ilişkisi altında ele aldığımızda net kârın, hasılat ve maliyet sürücülerinden meydana geldiğini (etkilendiğini) dolayısıyla maliyet ve/veya hasılatta meydana gelen değişimlerin net kârı etkilediğini söylemek mümkündür. Hasılat ve/veya maliyette meydana gelen artış ve azalışlar net kârı artırıp azaltmaktadır. Sürücü temelli bütçelemede işletme değer sürücü ağacı oluşturularak planlama ve bütçeleme faaliyetleri bu ağlarda meydana gelecek senaryolar göz önünde bulundurularak gerçekleştirilmektedir. Benzer şekilde süreç içerisinde meydana gelen değişiklikler sonucunda güncellemeler yapılmaktadır.

\section{SÜRÜCÜ TEMELLİ BÜTÇELEME MODELLERİ}

Sürücü temelli bütçelemede, bütçeleme süreci çoğunlukla satış departmanında talebin ölçülmesiyle başlamaktadır. Gelecek süreçte satılması beklenen ürünlerin, miktarların ve fiyatların bütçelere eklenmesiyle süreç başlatılmaktadır (Menon \& Thomas, 2021). Tüketici pazarlarındaki market hacmi, market büyüklüğü ve pazar payı, piyasa temelli modelde satış hacmi ve talebin sürücüleri olabilmektedir. İşletmeler arası piyasalardaki (b2b) modellerde satış miktarı ve pazarlama faaliyetleri talebin birincil sürücüsü olarak seçilebilmektedir. Burada önemli nokta, sürücü temelli bütçeleme modellerinin tamamında birincil girdi olarak talebin ölçülmesi gerektiği yanılgısına 
... (akademik, hakemli, indexli, uluslararası dergi)

düşülmemesidir. Belirli imalat ve tedarik endüstrilerinde, işletmelerin ticari olarak faaliyetlerinin sürdürebilmeleri için tesis ve varlıkların sürekli olarak kullanımda olması gerekir. Dolayısıyla bu durumda kapasite, sürücü temelli bütçelemenin birincil girdisi olmak durumundadır (Barrett, 2007, s. 70). Bütçeleme faaliyetlerini gerçekleştiren profesyoneller bu durumda planlamalarını talepten ziyade kapasiteye göre şekillendirmelidirler. Sürücü temelli bütçelemeye göre oluşturulacak üç model örneğine Şekil 2'de yer verilmektedir.

\section{Şekil 2. Sürücü Temelli Bütçeleme Modelleri}
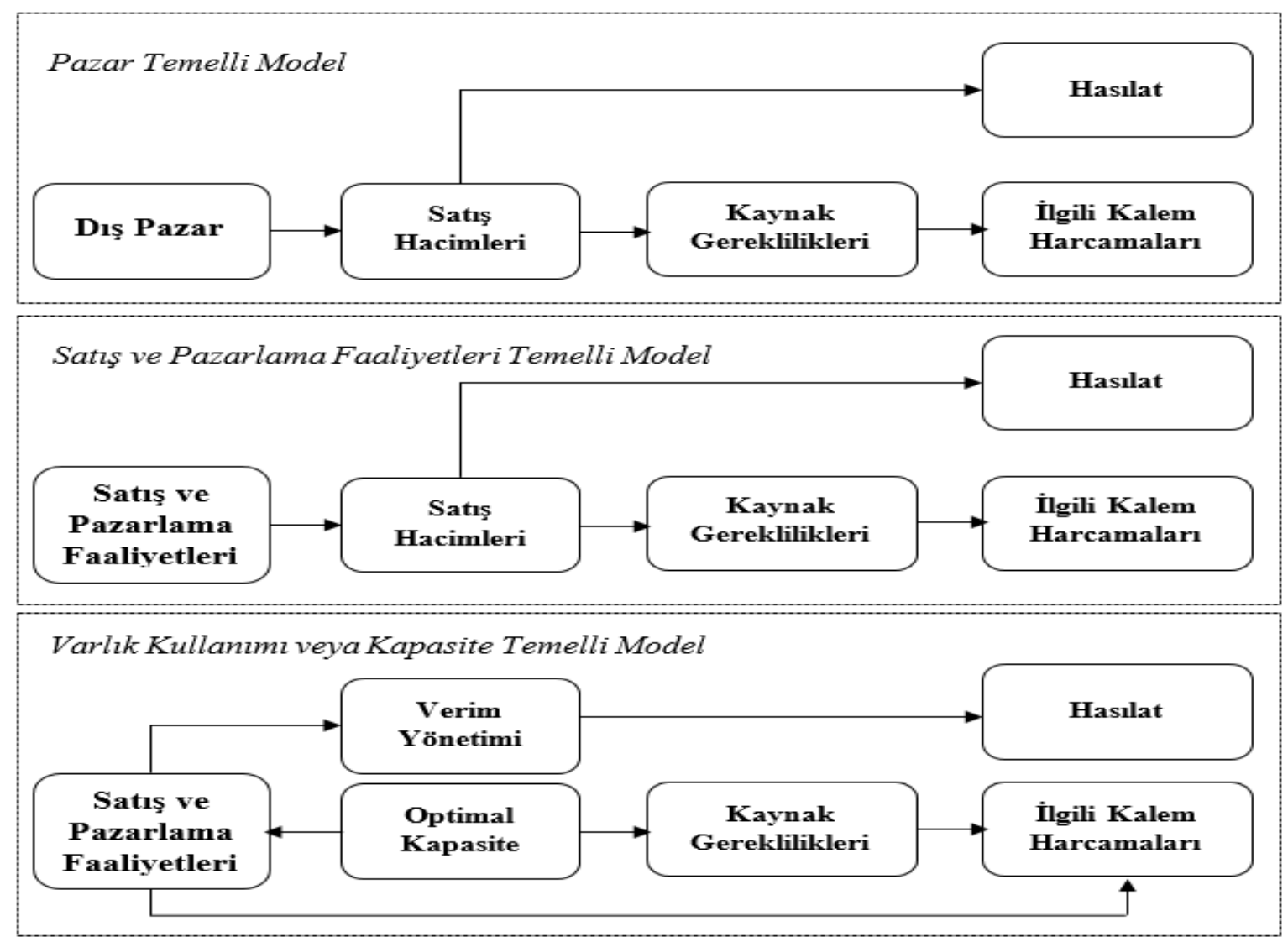

Kaynak: (Barrett, 2007, s. 73)

İşletmeler, Şekil 2'de yer alan modellerin haricinde de sürücü bütçeleme modelleri geliştirebilir. Söz konusu modellerde yer alan aşamalar ilgili birim ve kişilerce bütçeleme süreçlerine dâhil edilmelidir. Sürücü temelli bütçelemenin kullanımında Excel tablolarından yararlanılarak bir sistem kurulabilmektedir. Bunun ötesinde daha kompleks yapıdaki sürücü ağlarının oluşturulması ve bütçeleme sürecinde izlenebilmesi için çeşitli yazılımlardan* da yararlanılabilir (Deloitte, 2021). Yazılımların kullanılması durumunda bütçeleme adımlarının daha sağlıklı biçimde yürütülebilmesi, 
... (akademik, hakemli, indexli, uluslararası dergi)

birimler arası daha etkin koordinasyonun sağlanması ve bütçelerle ilgili güncellemelerde daha hılı bildirimler elde edilmesi mümkün olabilmektedir.

\section{SONUÇ}

Geleneksel bütçeleme yöntemleri günümüz işletmelerinin taleplerine ve/veya beklentilerine uygun (yeterli) olmadığı gerekçesiyle eleştirilmekte ve geleneksel araçların yerini yeni geliştirilen bütçeleme teknikleri almaktadır. Geleneksel bütçelere alternatif olarak geliştirilen sıfır tabanlı bütçeleme, faaliyet tabanlı bütçeleme, sürekli bütçeleme vb. bütçeleme araçlarından birisi de sürücü temelli bütçelemedir.

Sürücü temelli bütçelemede işletmenin performansı için değer sürücü ağı oluşturularak operasyonel eylemlerle bunların finnansal sonuçları eşleştirilmektedir. Bu açıdan sürücü tabanlı bütçelemenin neden-sonuç ilişkileri ve senaryolarla ilgili olduğunu söylemek mümkündür. Sürücü temelli bütçeleme, bütçe hazırlama ve/veya güncellemenin aldığı süreyi oldukça kısaltan bir bütçeleme modelidir. Ayrıca işletme kaynaklarının daha iyi kullanımını sağlayarak maliyet avantajı sağlamaktadır.

Sürücü temelli bütçelemenin çok sayıda yararı bulunmaktadır. Söz konusu bu faydalar değerlendirildiğinde önce çıkanların esneklik, geleceğe ilişkin daha doğru tahminler ve işletme birimlerinin koordinasyonuna katkı olduğunu söylemek mümkündür. Dezavantajları ele alındığında ise modelin uygulayıcılarca henüz tam olarak bilinmemesi ve uygulamasının nispeten güç olduğu karşımıza çıkmaktadır.

Sürücü temelli bütçelemenin olmazsa olmaz unsuru “sürücüler”dir. İşletmelerde sürücü temelli bütçeleme uygulamasında öncelikle sürücüler tespit edilmelidir. Her işletme için uygun, geçerli sayı ve türde sürücüden bahsetmek güçtür. Her işletme kendisi için uygun çeşit ve sayıda sürücü belirleyerek sürücü temelli bütçeleme uygulamasını gerçekleştirmek durumundadır.

Sürücü temelli bütçeleme konusunda gelecekte yapılacak çalışmalarda modelin farklı sektörlerdeki uygulama örneklerine yer verilebilir. $\mathrm{Bu}$ doğrultuda mamul ve/veya hizmet üretimi yapan işletmeler için sürecin nasıl gerçekleştirileceği, hangi modelin hangi işletme türleri için uygun olabileceği ve modelin geleneksel bütçeleme yaklaşımlarına kıyasla ne tür üstünlükleri olduğu ortaya konulabilir. 


\section{KAYNAKCA}

(akademik, hakemli, indexli, uluslararası dergi)

Barrett, R. (2007). Planning and Budgeting for the Agile Enterprise: A Driver-Based Budgeting Toolkit. Burlington: CIMA Publishing.

Becker, S., Messner, M., \& Schäffer, U. (2009). The Evolution of a Management Accounting Idea: The Case of Beyond Budgeting. Institute of Management Accounting and Control (IMC), 1-66.

Bogsnes, B. (2016). Implementing Beyond Budgeting - Unlocking the Performance Potential (Second Edition b.). New Jersey: John Wiley \& Sons.

Burrows, A. (2021). How to Define Value Drivers - a Simple Technique for Business Strategy and Performance Measurement. https://www.superchargedfinance.com/blog/how-to-define-value-drivers adresinden alınd 1

Coombs, H., Hobbs, D., \& Jenkins, E. (2005). Management Accounting - Principles and Applications (1st Edition b.). London: SAGE Publications.

Deloitte. (2021, 11 10). Driver-based forecasting: Is it the right approach for your company? www2.deloitte.com: https://www2.deloitte.com/us/en/pages/operations/articles/driver-basedplanning.html Erişim Tarihi: 12 Kasım 2021.

Eaton, G. (2005). CIMA Official Terminology 2005 Edition. The Chartered Institute of Management Accountants.

Essaides, N. (2016). AFP GUIDE: Driver-based Modeling and How it Works. www.AFPonline.org Erişim Tarihi: 11 Aralık 2021.

Hariharan, N. K. (2017). Predictive model building for driverbased budgeting using machine. Journal of Emerging Technologies and Innovative Research (JETIR), 4(6), 567-575.

https://valq.com/. (2021, 11 10). https://cdn.valq.com/wp-content/uploads/Value-Driver-Tree-SampleModel.png Erişim Tarihi: 9 Kasım 2021.

https://www.icaew.com/. (2021, 10 8). https://www.icaew.com/: https://www.icaew.com/technical/businessand-management/financial-management/budgeting/driver-based-budgeting Erişim Tarihi: 15 Kasım 2021.

Leon, L. D., Rafferty, P. D., \& Herschel, R. (2012). Replacing the Annual Budget with Business Intelligence Driver-Based Forecasts. Intelligent Information Management, 4, 6-12.

Melnychuk, L. (2017). Driver-Based Planning: Why is it So Important For Modern FP\&A?: https://fpatrends.com/report/driver-based-planning-why-it-so-important-modern-fpa Erişim Tarihi: 12 Aralık 2021.

Menon, R., \& Thomas, S. (2021). Scenario Based Analysis Using Driver Based Budgeting. World Economics \& Finance Bulletin (WEFB), 2, 28-30.

Miller, J., \& Galeaz, G. R. (2007). Ways to improve budgeting and forecasting: financial services companies should take a strategic approach to better link financial planning with strategic direction. Bank Accounting \& Finance, 20(5), 39-42. 
(akademik, hakemli, indexli, uluslararası dergi)

Nikodijević, M. (2021). Implications and challenges of using driver-based budgeting in contemporary business environment. Trendovi u poslovanju, 1(17), 49-57.

Rickards, R. C. (2006). Beyond Budgeting: Boon or Boondoggle? Investment Management and Financial Innovations, 3(2), 62-76.

Sanchez, J. (2020). Driver-Based Planning - Why and How. https://fpa-trends.com: https://fpatrends.com/article/driver-based-planning-why-and-how Erişim Tarihi: 12 Kasım 2021.

Wolf, R. (2015, 6 1). Broken budgets? https://sfmagazine.com/post-entry/june-2015-broken-budgets/ Erişim Tarihi: 17 Kasim 2021.

Çatışma Beyanı: Makalenin yazarı bu çalışma ile ilgili taraf olabilecek herhangi bir kişi ya da finansal ilişkileri bulunmadığını dolayısıyla herhangi bir çıkar çatışmasının olmadığını beyan eder.

Destek ve Teşekkür: Çalışmada herhangi bir kurum ya da kuruluştan destek alınmamıştır.

Etik Kurul Kararı: Bu araştırma, Etik Kurul Kararı gerektiren makaleler arasında yer almamaktadır. 